\title{
Predictors of oxygenation impairment in medical treatment for type B acute aortic dissection
}

\author{
Yusuke Kashiwagi ${ }^{1} \cdot$ Kimiaki Komukai $^{1} \cdot$ Kenichiro Suzuki $^{1} \cdot$ Yuhei Oi $^{1} \cdot$ Mitsutoshi Tominaga $^{1} \cdot$ Kotaro Nakata $^{1}$. \\ Satoru Miyanaga ${ }^{1} \cdot$ Tetsuya Ishikawa $^{1} \cdot$ Kosuke Minai $^{2} \cdot$ Tomohisa Nagoshi $^{2} \cdot$ Michihiro Yoshimura $^{2}$
}

Received: 24 February 2018 / Accepted: 1 June 2018 / Published online: 4 June 2018

(c) Springer Japan KK, part of Springer Nature 2018

\begin{abstract}
Lung oxygenation impairment often occurs in patients with type B acute aortic dissection (AAD), necessitating mechanical ventilation. Patients receiving mechanical ventilation are at risk of complications, so a low-oxygen condition requiring mechanical ventilation should be avoided. We explored the predictors of oxygenation impairment. We enrolled 46 patients with type B AAD who had been medically treated and underwent computed tomography. Blood was sampled to measure markers of inflammation, such as the C-reactive protein (CRP) levels and white blood cell count. The arterial partial pressure of oxygen/fraction of inspired oxygen ratio $\left(\mathrm{PaO}_{2} / \mathrm{FiO}_{2}\right)$ was calculated to quantify the severity of respiratory failure. Spearman's rank correlation analysis revealed that the minimum $\mathrm{PaO}_{2} / \mathrm{FiO}_{2}$ ratio was significantly correlated with gender, age, and current smoker, and the peak CRP, body temperature, and D-dimer values. A multivariate regression analysis revealed that younger age, male sex, and the peak CRP level were significant predictors of the minimum $\mathrm{PaO}_{2} / \mathrm{FiO}_{2}$ ratio $(P=0.01,0.035$ and 0.005 , respectively). A covariance structure analysis showed that a younger age and the peak CRP level were significant predictors of oxygenation impairment in type B AAD. Oxygenation impairment in type B AAD is correlated with younger age and a higher peak CRP level. This will enable the identification of patients whose respiratory condition is susceptible to worsening and help prevent mechanical ventilation, leading to the provision of appropriate therapy.
\end{abstract}

Keywords Acute aortic dissection · Oxygenation impairment · Vascular permeability · Inflammation · Pulmonary connective tissue

\section{Introduction}

Patients with type $B$ acute aortic dissection (AAD) have a better prognosis than those with type A AAD, and they are initially managed with medical therapy, such as antihypertensive treatment. However, some type B AAD patients suffer from lung oxygenation impairment, which necessitates mechanical ventilation. Patients receiving mechanical ventilation are at risk of certain complications, such as ventilator-associated pneumonia (VAP) and ventilator-associated lung injury (VILI) [1-3]. VAP causes substantial morbidity by increasing

Yusuke Kashiwagi

y-kashiwa@jikei.ac.jp

1 Division of Cardiology, Department of Internal Medicine, The Jikei University School of Medicine, Kashiwa Hospital, 163-1 Kashiwashita, Kashiwa, Chiba 277-8567, Japan

2 Division of Cardiology, Department of Internal Medicine, The Jikei University School of Medicine, Tokyo, Japan the duration of mechanical ventilation and intensive-care unit (ICU) stay [4, 5]. It is, therefore, important to avoid low-oxygen conditions that necessitate mechanical ventilation.

Previous studies have shown that oxygenation impairment is associated with a systemic inflammatory reaction and the degree of aortic injury [6-9]. However, in patients with aortic dissection, the inflammatory marker levels peak several days after the onset and are, therefore, inadequate for predicting oxygenation impairment at the time of admission.

The aim of this study was to identify other clinical risk factors associated with oxygenation impairment in patients with type B AAD at the early stage of hospitalization.

\section{Methods}

Between December 2010 and May 2017, 67 patients diagnosed with type B AAD were admitted to our institution. We excluded patients who were admitted more than $24 \mathrm{~h}$ 
after the onset of symptoms $(n=8)$, and who underwent emergency surgical treatment $(n=3)$. Patients with infectious disease $(n=7)$, respiratory disease such as interstitial pneumonia $(n=2)$, and cardiac hypofunction (left ventricular ejection fraction $<50 \%)(n=1)$ were also excluded. After applying these selection criteria, 46 patients were suitable for inclusion in the analysis.

Data regarding the patients' backgrounds and clinical findings were retrospectively collected from their medical records. The patients' background data included their age, gender, body mass index, and current smoking habit. Blood samples were collected on the day of admission and every $24 \mathrm{~h}$ thereafter for at least 4 days. We measured the serum C-reactive protein (CRP) levels, white blood cell (WBC) count, and platelet count to assess the severity of inflammation. The arterial partial pressure of oxygen/fraction of inspired oxygen ratio $\left(\mathrm{PaO}_{2} / \mathrm{FiO}_{2}\right)$ was calculated to quantify the severity of respiratory failure. The estimated $\mathrm{FiO}_{2}$ level was adopted as the $\mathrm{FiO}_{2}$ value in patients who did not receive mechanical ventilation support [10].

The diagnosis of type B AAD was made based on the results of contrast medium-enhanced computed tomography (CT). CT scans were performed with a slice thickness of $5 \mathrm{~mm}$. We measured the range of aortic dissection in the longitudinal direction and the maximum diameter of aortic dissection on transverse sections. The study was approved by the medical ethics committee of the Jikei University School of Medicine.

\section{Statistical analyses}

Data are expressed as the mean \pm standard error (SE) or as the median (25th, 75th percentile) for significantly skewed variables. Correlations between the minimum $\mathrm{PaO}_{2} / \mathrm{FiO}_{2}$ ratio and parameters of inflammation were assessed using Spearman's rank correlation coefficient. Variables that were not statistically significant (i.e., $P>0.05$ ) were excluded from further analyses. A stepwise multiple linear regression analysis was performed to determine the contribution of various clinical variables to the minimum $\mathrm{PaO}_{2} /$ $\mathrm{FiO}_{2}$ ratio. Two-tailed $P$ values of $<0.05$ were considered to indicate statistical significance. All statistical analyses were performed using the SPSS Statistics software program (version 24.0, SPSS Inc., Chicago, IL, USA).

We cannot rule out the possibility that some clinical factors in this study confounded each other; thus, the ability of the multiple regression analysis to determine the true relationship was limited. We added another investigation using a path analysis based on a covariate structure analysis, similarly to previous studies [11-15]. A path model based on a covariance structure analysis was proposed to investigate the relationships among clinical factors and specifically to identify probable causal effects on the minimum $\mathrm{PaO}_{2} / \mathrm{FiO}_{2}$ ratio. The causality model defined some hierarchical regression models between clinical factors and the minimum $\mathrm{PaO}_{2} / \mathrm{FiO}_{2}$ ratio. The path analysis was performed using the IBM SPSS AMOS software program (version 24; Amos Development Corporation, Meadville, PA, USA). The structural equation models that were obtained were tested and confirmed at a significance level of $P<0.05$.

\section{Results}

Table 1 shows the clinical characteristics of the patients in this study. Table 2 shows Spearman's rank correlation coefficients of the minimum $\mathrm{PaO}_{2} / \mathrm{FiO}_{2}$ ratio with the clinical variables. The minimum $\mathrm{PaO}_{2} / \mathrm{FiO}_{2}$ was significantly and positively correlated with the age $(r=0.518, P<0.001)$ and was negatively correlated with gender $(r=-0.294, P=0.048)$, a current smoking habit $(r=-0.322, P=0.029)$, and the peak CRP $(r=-0.483, P=0.001)$, body temperature $(r=-0.415$, $P=0.004)$, and $\mathrm{D}$-dimer $(r=-0.332, P=0.024)$ values (Fig. 1).

Stepwise multivariate linear regression analyses to determine the predictors of the minimum $\mathrm{PaO}_{2} / \mathrm{FiO}_{2}$ ratio initially included gender, age, current smoker, peak CRP level, peak body temperature, and peak D-dimer level as predictive variables. Variables with the weakest association were sequentially deleted from the models, leaving three (age, gender, and peak CRP) variables in the final model (Table 3).

The proposed theoretical path model is shown in Fig. 2. The path model included age, gender, current smoker, and peak CRP; correlations between any two of these factors were indicated using two arrows. The paths between variables were drawn from independent variables to dependent variables with directional arrows - namely from age, gender, peak CRP, and current smoker to the minimum $\mathrm{PaO}_{2} / \mathrm{FiO}_{2}$ ratio.

The results of the statistical analysis are shown in Table 4. After standardizing all variables, the model showed that the minimum $\mathrm{PaO}_{2} / \mathrm{FiO}_{2}$ ratio was predicted by age (standardized regression coefficients, $\beta$ : $-0.30, P=0.010$ ) and the peak CRP level $(\beta:-0.38, P=0.001)$. These data reinforced that a younger age and a higher peak CRP level were correlated with oxygenation impairment in type B AAD.

Table 5 shows Spearman's rank correlation coefficients of age with the clinical variables. Age was significantly and positively correlated with high-density lipoprotein (HDL) $(r=0.335, P=0.026)$ and B-type natriuretic peptide (BNP) $(r=0.361, P=0.016)$, and was negatively correlated with the body mass index $(r=-0.498, P<0.001)$, diastolic blood pressure $(r=-0.295, P=0.047)$, triglyceride (TG) $(r=-0.325, P=0.028)$, WBC at admission $(r=-0.431$, 
Table 1 Clinical characteristics of the patients. $(n=46)$

\begin{tabular}{|c|c|}
\hline Male $(\%)$ & 78.3 \\
\hline Age (years) & $67 \pm 1.7$ \\
\hline Body mass index $\left(\mathrm{kg} / \mathrm{m}^{2}\right)$ & $24.1 \pm 0.51$ \\
\hline Systolic blood pressure (mmHg) & $177 \pm 5.3$ \\
\hline Diastolic blood pressure (mmHg) & $100 \pm 3.2$ \\
\hline Heart rate (beats per minutes) & $74 \pm 2.2$ \\
\hline Current smoker (\%) & 39.1 \\
\hline Creatinine (mg/dl) & $0.85(0.72,0.99)$ \\
\hline $\mathrm{HDL}(\mathrm{mg} / \mathrm{dl})$ & $51.7 \pm 1.6$ \\
\hline $\mathrm{LDL}(\mathrm{mg} / \mathrm{dl})$ & $115 \pm 4.1$ \\
\hline $\mathrm{TG}(\mathrm{mg} / \mathrm{dl})$ & $126(78,210)$ \\
\hline HbA1c (\%) & $5.8(5.6,6.0)$ \\
\hline Glucose (mg/dl) & $128(112,151)$ \\
\hline $\mathrm{BNP}(\mathrm{pg} / \mathrm{ml})$ & $30.2(16.0,57.3)$ \\
\hline Lesion length of aortic dissection (mm) & $302 \pm 15.3$ \\
\hline Maximum aneurysm diameter (mm) & $39.6(34.8,43.0)$ \\
\hline DeBakey IIIa/IIIb $(n)$ & $6 / 40$ \\
\hline Patency rate of false lumen (\%) & 41.3 \\
\hline WBC (admission) $(/ \mu \mathrm{l})$ & $8600(7050,10,900)$ \\
\hline CRP (admission) (mg/dl) & $0.10(0.10,0.43)$ \\
\hline Body temperature (admission) $\left({ }^{\circ} \mathrm{C}\right)$ & $36.8 \pm 0.11$ \\
\hline The timing of peak body temperature (days) & $3(2,6)$ \\
\hline Peak WBC $(/ \mu \mathrm{l})$ & $12,000(10,500,14,700)$ \\
\hline Peak CRP (mg/dl) & $14.2 \pm 0.74$ \\
\hline The timing of peak CRP (day) & $5(4,6)$ \\
\hline Peak body temperature $\left({ }^{\circ} \mathrm{C}\right)$ & $38.0 \pm 0.07$ \\
\hline Peak D-dimer $(\mu \mathrm{g} / \mathrm{ml})$ & $18.1(8.75,38.4)$ \\
\hline Length of CCU stay (day) & $9.0(7.0,16.5)$ \\
\hline Use of ventilator (\%) & 32.6 \\
\hline Minimum $\mathrm{PaO}_{2} / \mathrm{FiO}_{2}$ ratio & $87.0(66.9,229)$ \\
\hline $\begin{array}{l}\text { The timing of minimum } \mathrm{PaO}_{2} / \mathrm{FiO}_{2} \text { ratio } \\
\text { (day) }\end{array}$ & $3(3,5)$ \\
\hline Pleural effusion $(\%)$ & 93.5 \\
\hline \multicolumn{2}{|l|}{ Antihypertensive agent (at CCU) } \\
\hline$\beta$ Blocker $(\%)$ & 100 \\
\hline $\mathrm{Ca}$ antagonist $(\%)$ & 100 \\
\hline ARB/ACE-I (\%) & 78.3 \\
\hline Nitroglycerin (\%) & 52.2 \\
\hline
\end{tabular}

$H D L$ high-density lipoprotein, $L D L$ low-density lipoprotein, $T G$ triglyceride, $B N P$ B-type natriuretic peptide, $W B C$ white blood cell, $C R P$ C-reactive protein, $C C U$ coronary care unit, $A R B$ angiotensin II receptor blockers, $A C E-I$ angiotensin-converting enzyme inhibitors

$P=0.003)$, peak WBC $(r=-0.477, P=0.001)$, peak body temperature $(r=-0.341, P=0.021)$, and the ventilator use rate $(r=-0.346, P=0.018)$.

In Fig. 3, the study patients with type B AAD were grouped according to age, in addition, they were also divided according to the absence or presence of oxygenation impairment. The histogram showed that the younger group included patients with worse respiratory conditions.
Table 2 Spearman's rank correlation coefficients of the minimum $\mathrm{PaO}_{2} / \mathrm{FiO}_{2}$ ratio with clinical factors

\begin{tabular}{lrr}
\hline & $r$ & \multicolumn{1}{r}{$P$} \\
\hline Male & -0.294 & 0.048 \\
Age & 0.518 & $<0.001$ \\
Body mass index & -0.271 & 0.068 \\
Systolic blood pressure & -0.211 & 0.160 \\
Diastolic blood pressure & -0.185 & 0.219 \\
Heart rate & 0.225 & 0.134 \\
Current smoker (\%) & -0.322 & 0.029 \\
Creatinine & -0.160 & 0.290 \\
HDL & 0.039 & 0.802 \\
LDL & -0.181 & 0.234 \\
TG & -0.187 & 0.212 \\
HbA1c & 0.035 & 0.818 \\
Glucose & 0.068 & 0.659 \\
BNP & 0.204 & 0.185 \\
Lesion length of aortic dissection & -0.232 & 0.120 \\
Maximum aneurysm diameter & -0.146 & 0.333 \\
Debakey IIIb (\%) & -0.039 & 0.797 \\
Patency rate of false lumen (\%) & -0.181 & 0.228 \\
WBC (admission) & -0.236 & 0.114 \\
CRP (admission) & 0.118 & 0.436 \\
Body temperature (admission) & 0.035 & 0.816 \\
Peak WBC & -0.247 & 0.098 \\
Peak CRP & -0.483 & 0.001 \\
Peak body temperature & -0.415 & 0.004 \\
Peak D-dimer & -0.332 & 0.024 \\
Length of CCU stay & -0.498 & $<0.001$ \\
Use of ventilator (\%) & -0.655 & $<0.001$ \\
Pleural effusion (\%) & -0.368 & 0.012 \\
Antihypertensive agent (at CCU) & & 0.793 \\
ARB/ACE-I (\%) & -0.0482 \\
Nitroglycerin (\%) & & 0.588 \\
\hline
\end{tabular}

$H D L$ high-density lipoprotein, $L D L$ low-density lipoprotein, $T G$ triglyceride, $B N P$ B-type natriuretic peptide, $W B C$ white blood cell, $C R P$ C-reactive protein, $C C U$ coronary care unit, $A R B$ angiotensin II receptor blockers, $A C E-I$ angiotensin-converting enzyme inhibitors

\section{Discussion}

In the present study, we identified the clinical risk factors for oxygenation impairment at the early stage of hospitalization in patients with type B AAD and concluded that younger age and a higher peak CRP level were correlated with the minimum $\mathrm{PaO}_{2} / \mathrm{FiO}_{2}$ ratio.

Kurabayashi et al. found that respiratory failure appears to be closely correlated with the degree of aortic injury measured by a CT-based index of AAD volume 

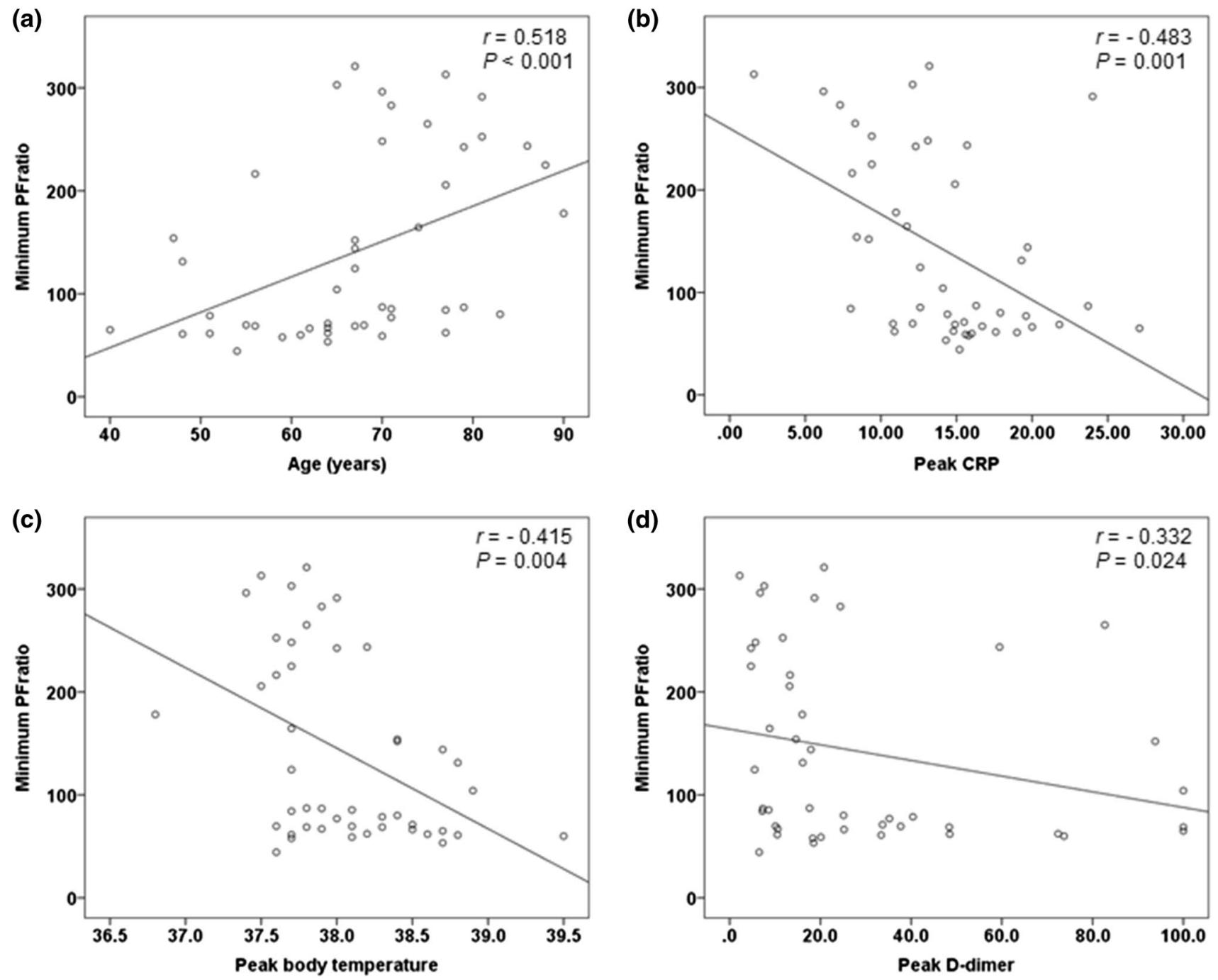

Fig. 1 a The relationship between the minimum PF ratio and age. b Relationship between the minimum PF ratio and the peak CRP. $\mathbf{c}$ The relationship between the minimum PF ratio and peak body tempera-

ture. $\mathbf{d}$ The relationship between the minimum PF ratio and the peak D-dimer. $P F$ ratio $\mathrm{PaO}_{2} / \mathrm{FiO}_{2}$ ratio

Table 3 A multivariable linear regression analysis of the factors associated with the minimum $\mathrm{PaO}_{2} / \mathrm{FiO}_{2}$ ratio

\begin{tabular}{lccrl}
\hline $\begin{array}{l}\text { Minimum } \\
\mathrm{PaO}_{2} / \mathrm{FiO}_{2} \text { ratio }\end{array}$ & Coefficient & Standard error & $t$ & $P$ \\
\hline Age & 2.629 & 0.968 & 2.716 & 0.010 \\
Male & -56.6 & 25.902 & -2.185 & 0.035 \\
Peak CRP & -6.522 & 2.208 & -2.953 & 0.005 \\
\hline
\end{tabular}

$C R P$ C-reactive protein

(performed to evaluate the extent of type B AAD), and that it is possibly mediated by the magnitude of the systemic inflammatory reaction to the aortic injury [8]. Tomita et al. showed that a higher BMI, relatively higher body temperature on the admission day, and lower $\mathrm{PaO}_{2} / \mathrm{FiO}_{2}$ on

admission were reliable for predicting oxygen impairment [9]. However, since it is undeniable that various clinical factors related to AAD confounded each other in these studies, we investigated the clinical factors associated with respiratory failure in type $\mathrm{B}$ AAD by performing a path analysis based on covariance structure analysis as well as a multiple regression analysis.

Previous reports have shown that increases in CRP are related to lung oxygenation impairment in patients with AAD $[7,16,17]$. In the present study, we reached the same conclusion as previous studies. These studies explained that CRP is correlated with oxygenation impairment through the production of inflammatory cytokines, such as interleukin-6 (IL-6) and IL8.

In the present study, we clarified-for the first time- that younger age was an independent predictor 


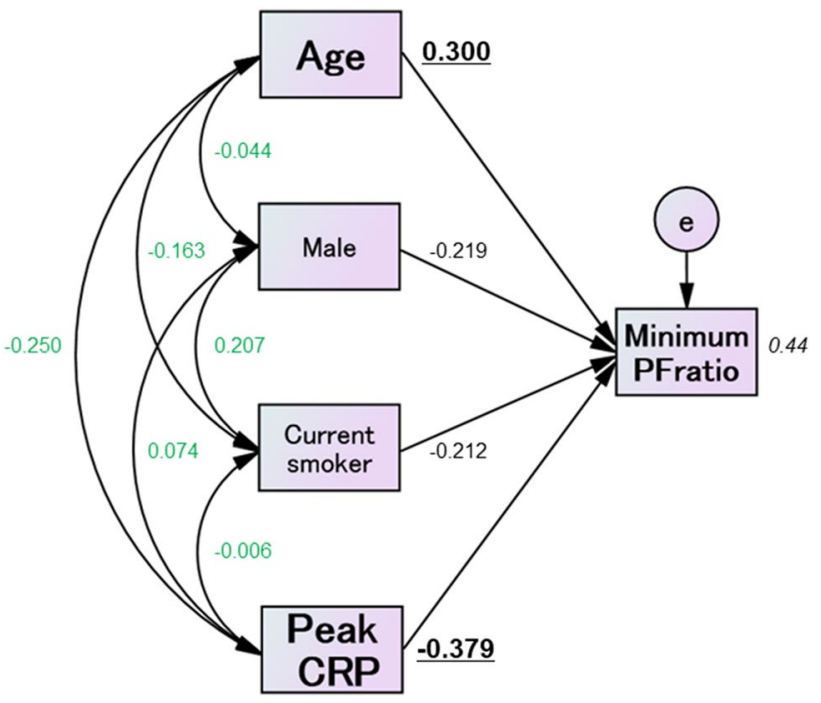

Fig. 2 The path model. Each path has a coefficient representing the standardized coefficient of a regressing independent variable on a dependent variable of the relevant path. These variables represent the standardized regression coefficients (direct effect) (underlined portions indicate remarkable values), squared multiple correlations (in narrow italics), and correlations among exogenous variables (green). PF ratio $\mathrm{PaO}_{2} / \mathrm{FiO}_{2}$ ratio

Table 4 A standardized regression coefficient analysis to identify the clinical factors influencing the minimum $\mathrm{PaO}_{2} / \mathrm{FiO}_{2}$ ratio in the path model

\begin{tabular}{lcc}
\hline Clinical factor & Direct effect & $P$ \\
\hline Minimum $\mathrm{PaO}_{2} / \mathrm{FiO}_{2}$ ratio & & \\
Age & 0.30 & 0.010 \\
Male & -0.22 & 0.055 \\
Current smoker & -0.21 & 0.067 \\
Peak CRP & -0.38 & 0.001 \\
\hline
\end{tabular}

of oxygenation impairment in AAD in multivariate and covariance structure analyses. We found no reports in the literature that clearly stated that younger age exacerbates the respiratory condition of AAD patients. We considered that there were two reasons for the relationship between a younger age and respiratory failure.

First, it is vascular permeability, which develops in AAD patients. The precise mechanism through which pleural effusion accumulates after the onset of aortic dissection is not well understood. AAD is frequently accompanied by lung oxygenation impairment [8], and the acute phase of respiratory failure is characterized by the influx of proteinrich edema fluid into the air spaces as a consequence of the increased permeability of the alveolar-capillary barrier [18]. In general, aging is a major risk factor for microvascular
Table 5 Spearman's rank correlation coefficients of age with clinical factors

\begin{tabular}{lrr}
\hline & $r$ & $P$ \\
\hline Body mass index & -0.498 & $<0.001$ \\
Systolic blood pressure & -0.056 & 0.712 \\
Diastolic blood pressure & -0.295 & 0.047 \\
Heart rate & 0.018 & 0.903 \\
Current smoker (\%) & -0.197 & 0.190 \\
Creatinine & -0.164 & 0.275 \\
HDL & 0.335 & 0.026 \\
LDL & -0.077 & 0.615 \\
TG & -0.325 & 0.028 \\
HbA1c & -0.077 & 0.609 \\
Glucose & 0.055 & 0.719 \\
BNP & 0.361 & 0.016 \\
Lesion length of aortic dissection & -0.205 & 0.172 \\
Maximum aneurysm diameter & -0.090 & 0.550 \\
Debakey IIIb (\%) & -0.170 & 0.257 \\
Patency rate of false lumen (\%) & -0.203 & 0.176 \\
WBC (admission) & -0.431 & 0.003 \\
CRP (admission) & -0.049 & 0.745 \\
Body temperature (admission) & 0.001 & 0.995 \\
Peak WBC & -0.477 & 0.001 \\
Peak CRP & -0.220 & 0.141 \\
Peak body temperature & -0.341 & 0.021 \\
Peak D-dimer & -0.227 & 0.130 \\
Length of CCU stay & -0.285 & 0.055 \\
Use of ventilator (\%) & -0.346 & 0.018 \\
Pleural effusion (\%) & -0.140 & 0.355 \\
Antihypertensive agent (at CCU) & & \\
ARB/ACE-I (\%) & -0.231 & 0.123 \\
Nitroglycerin (\%) & -0.227 & 0.130 \\
\hline & & \\
\hline
\end{tabular}

dysfunction and hyperpermeability. As one grows older, oxidative stress, inflammation, and the activation of apoptotic signaling increase, and promote endothelial dysfunction and their relationship to hyperpermeability [19]. This study showed the opposite, in that younger age was correlated with oxygenation impairment in type B AAD. Some studies have shown that the respiratory failure in AAD was influenced by systemic inflammatory reactions $[6,7,16]$; at the same time, local inflammatory reactions also exert influence on the respiratory condition. Previous reports have revealed that predominantly left-sided pleural effusion is a common finding in type B AAD because the left pleura are in contact with the large thoracic arteries [20,21]. Inflammation of the aorta from dissection could irritate the pleura, leading to reactionary effusion. Millonig et al. demonstrated that mast cells were detectable in the intima and adventitia of thoracic and abdominal aorta in American subjects of 15-34 years of age without cardiovascular disease [22]. Mast cells were 
Fig. 3 Histogram of the study patients with type B acute aortic dissection according to age. The histogram of the study population was divided according to the absence or presence of oxygenation impairment. Oxygenation impairment was defined by a minimum $\mathrm{PaO}_{2} /$ $\mathrm{FiO}_{2}$ ratio of $<200$

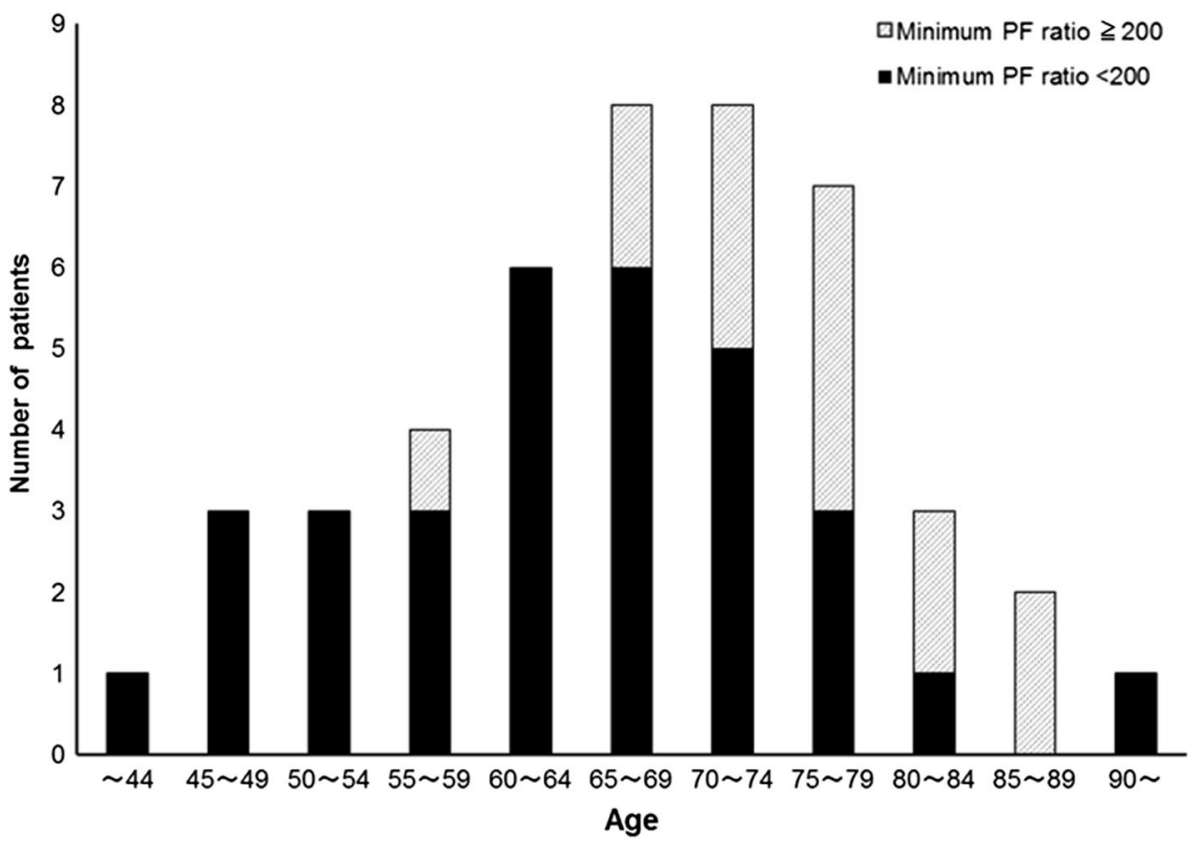

more frequently found in the adventitia than anywhere else in the arterial wall in patients with severe atherosclerotic lesions. Furthermore, mast cells were shown to release some chemical mediators that are associated with the development of atherosclerosis and aneurysm formation [23]. On the other hand, mast cells also release histamine and vascular endothelial growth factors (VEGF) that increase vascular permeability [24-26]. Tsuboi et al. suggested that mast-cell development declines with aging due to stromal-cell functional impairment, which contributes to immunosenescence [27]. Taken together, younger age was correlated with respiratory failure because increased levels of chemical mediators from mast cells increase vascular permeability.

Second, congenital abnormalities might be involved in the development of aortic dissection at a young age. Several inherited connective tissue disorders have been reported, including Marfan syndrome, Loeys-Dietz syndrome, and Ehlers-Danlos syndrome [28]. In particular, Marfan syndrome is characterized by the presence of disproportionate overgrowth of the long bone, ectopia lentis, and aortic root aneurysm [29]. Although pulmonary symptoms are not generally considered a main feature of Marfan syndrome, many patients have a degree of underlying pulmonary pathology [30]. The histologic findings in relation to the pulmonary changes in Marfan syndrome include interstitial parenchymal disease and honeycombing, diffuse and apical bullous emphysema, and congenital malformations of the bronchus, bronchiectasis, and spontaneous pneumothorax $[31,32]$. These abnormalities of the lung may occur due to weakness of the pulmonary connective tissue fibers in Marfan syndrome [33]. The lung is histologically composed of elastic fiber [34, 35], and previous reports have shown that the lungs of children with Marfan syndrome show precocious maturation of the elastic stroma of the alveolar septa [36].

None of the patients in the present study had been diagnosed with genetically mediated collagen disorders such as Marfan syndrome; however, the possibility cannot be ruled out that other unknown genetic defects of connective tissue were present in these younger patients. Aortic dissection used to be clearly defined as a pathological condition characterized by the presence of an aortic intimal tear and medial dissection, making it a condition in which blood flows from the entry site into the false lumen. Medial elastic fiber degeneration and macrophage accumulation were observed before the development of aortic dissection, suggesting the possibility that structural abnormalities of the elastic fibers induced aortic dissection [37]. We may reasonably conclude that medial weakness most likely occurs due to the structural abnormalities of elastic fibers, the main component of the media. Patients who develop aortic dissection at a relatively young age may have a systemic weakness of their elastic fibers and may, therefore, be susceptible to a worsening of respiratory failure.

We showed that age was significantly correlated with the WBC count (peak and admission) and peak body temperature. These results indicated that diminished inflammatory responses with age may function as a biological explanation for the observed decline in the risk of lung oxygenation impairment.

In the present study, we concluded that a younger age was an independent predictor of lung oxygenation impairment in type B AAD. Lung oxygenation impairment during the acute phase of aortic dissection may develop by the same mechanism as acute respiratory distress syndrome (ARDS). The influence of age differs according to the underlying disease of ARDS. 
Gee et al. reported that, in all-cause ARDS patients, the $\mathrm{PaO}_{2} /$ $\mathrm{FiO}_{2}$ ratio among patients of $\geq 60$ years of age was higher (i.e., lung oxygenation was better) than that in younger patients [38]. Seethala et al. showed that younger age was associated with an increased risk of developing ARDS in patients with sepsis, which is the most common cause of ARDS [39]. Conversely, Danner et al. reported that in patients with septic shock, the incidence of ARDS among patients of $\geq 50$ years of age was 2.8 times higher than that in younger patients [40]. We thought that this discrepancy between the two reports was due to differences in the study backgrounds, such as the age groups of the cohorts and the methods of treatment, which varied according to the time of the study. Watkins et al. showed that older age was an independent predictor of trauma-associated ARDS in trauma patients [41]. Johnston et al. reported that the risk of ARDS developing in response to trauma peaked at 60-69 years of age and then actually declined in the oldest patients (i.e., patients of $\geq 70$ years of age) [42].

\section{Study limitations}

The present study was associated with several limitations. This study was conducted at a single university hospital, the study population was small, and the data were collected retrospectively. In addition, the $\mathrm{PaO}_{2} / \mathrm{FiO}_{2}$ ratio in patients with spontaneous breathing was an estimated value; however, we believe that it reflected the general respiratory status of the patients.

\section{Conclusion}

The oxygenation impairment in type B AAD is closely correlated with a younger age and a higher peak CRP level. These findings will facilitate the identification of patients who are susceptible to a worsening respiratory condition, thereby leading to more appropriate therapeutic management and the prevention of unnecessary mechanical ventilation.

Acknowledgements We would like to thank Brian Quinn, Japan Medical Communication, for reading the manuscript. This research received no grant from any funding agency in the public, commercial, or notfor-profit sectors.

\section{Compliance with ethical standards}

Conflict of interest The authors declare no conflicts of interest in association with the present study.

\section{References}

1. (1999) International consensus conferences in intensive care medicine: Ventilator-associated Lung Injury in ARDS. This official conference report was cosponsored by the American Thoracic Society, The European Society of Intensive Care Medicine, and The Societe de Reanimation de Langue Francaise, and was approved by the ATS Board of Directors, July 1999. Am J Respir Crit Care Med 160:2118-2124

2. Cook DJ, Walter SD, Cook RJ, Griffith LE, Guyatt GH, Leasa D, Jaeschke RZ, Brun-Buisson C (1998) Incidence of and risk factors for ventilator-associated pneumonia in critically ill patients. Ann Intern Med 129:433-440

3. Tobin MJ (1994) Mechanical ventilation. N Engl J Med 330:1056-1061

4. Fagon JY, Chastre J, Vuagnat A, Trouillet JL, Novara A, Gibert C (1996) Nosocomial pneumonia and mortality among patients in intensive care units. JAMA 275:866-869

5. Papazian L, Bregeon F, Thirion X, Gregoire R, Saux P, Denis JP, Perin G, Charrel J, Dumon JF, Affray JP, Gouin F (1996) Effect of ventilator-associated pneumonia on mortality and morbidity. Am J Respir Crit Care Med 154:91-97

6. Hasegawa Y, Ishikawa S, Ohtaki A, Otani Y, Takahashi T, Sato Y, Koyano T, Yamagishi T, Ohki S, Kanda T, Morishita Y (1999) Impaired lung oxygenation in acute aortic dissection. J Cardiovasc Surg (Torino) 40:191-195

7. Komukai K, Shibata T, Mochizuki S (2005) C-reactive protein is related to impaired oxygenation in patients with acute aortic dissection. Int Heart J 46:795-799

8. Kurabayashi M, Okishige K, Azegami K, Ueshima D, Sugiyama K, Shimura T, Maeda M, Aoyagi H, Isobe M (2010) Reduction of the $\mathrm{PaO}_{2} / \mathrm{FiO}_{2}$ ratio in acute aortic dissection-relationship between the extent of dissection and inflammation. Circ $\mathbf{J}$ 74:2066-2073

9. Tomita K, Hata N, Kobayashi N, Shinada T, Shirakabe A (2014) Predicting the occurrence of oxygenation impairment in patients with type-B acute aortic dissection. Int J Angiol 23:53-60

10. Ba IS, Kacmarek R, Cane R, Peruzzi W, Hauptman D (1991) Clinical application of respiratory care, 4th edn. Mosby Year Book, St. Louis

11. Ogawa K, Minai K, Kawai M, Tanaka T, Nagoshi T, Ogawa T, Yoshimura M (2017) Parallel comparison of risk factors between progression of organic stenosis in the coronary arteries and onset of acute coronary syndrome by covariance structure analysis. PLoS One 12:e0173898

12. Tsutsumi J, Minai K, Kawai M, Ogawa K, Inoue Y, Morimoto S, Tanaka T, Nagoshi T, Ogawa T, Yoshimura M (2017) Manifold implications of obesity in ischemic heart disease among Japanese patients according to covariance structure analysis: low reactivity of B-type natriuretic peptide as an intervening risk factor. PLoS One 12:e0177327

13. Tanaka Y, Nagoshi T, Kawai M, Uno G, Ito S, Yoshii A, Kimura $\mathrm{H}$, Inoue $\mathrm{Y}$, Ogawa K, Tanaka TD, Minai K, Ogawa T, Yoshimura M (2017) Close linkage between serum uric acid and cardiac dysfunction in patients with ischemic heart disease according to covariance structure analysis. Sci Rep 7:2519

14. Fukumoto R, Kawai M, Minai K, Ogawa K, Yoshida J, Inoue Y, Morimoto S, Tanaka T, Nagoshi T, Ogawa T, Yoshimura M (2017) Conflicting relationship between age-dependent disorders, valvular heart disease and coronary artery disease by covariance structure analysis: possible contribution of natriuretic peptide. PLoS One 12:e181206

15. Ito S, Nagoshi T, Minai K, Kashiwagi Y, Sekiyama H, Yoshii A, Kimura H, Inoue Y, Ogawa K, Tanaka TD, Ogawa T, Kawai M, Yoshimura M (2017) Possible increase in insulin resistance and concealed glucose-coupled potassium-lowering mechanisms during acute coronary syndrome documented by covariance structure analysis. PLoS One 12:e176435

16. Sugano Y, Anzai T, Yoshikawa T, Satoh T, Iwanaga S, Hayashi T, Maekawa Y, Shimizu H, Yozu R, Ogawa S (2005) Serum 
C-reactive protein elevation predicts poor clinical outcome in patients with distal type acute aortic dissection: association with the occurrence of oxygenation impairment. Int J Cardiol 102:39-45

17. Jo Y, Anzai T, Sugano Y, Naito K, Ueno K, Kohno T, Yoshikawa T, Ogawa S (2008) Early use of beta-blockers attenuates systemic inflammatory response and lung oxygenation impairment after distal type acute aortic dissection. Heart Vessels 23:334-340

18. Ware LB, Matthay MA (2000) The acute respiratory distress syndrome. N Engl J Med 342:1334-1349

19. Oakley R, Tharakan B (2014) Vascular hyperpermeability and aging. Aging Dis 5:114-125

20. Patris V, Whiteley J, Argiriou O, Lama N, Georgiou H, Constantinou C, Argiriou M, Charitos C (2014) Pyrexia in patients with uncontrolled systemic hypertension: could they have an aortic dissection? J Thorac Dis 6:E246-E248

21. Schattner A, Klepfish A (2012) Left pleural effusion and fever of unknown origin - a clue to thoracic arterial pathology. J Gen Intern Med 27:1084-1087

22. Millonig G, Malcom GT, Wick G (2002) Early inflammatoryimmunological lesions in juvenile atherosclerosis from the Pathobiological Determinants of Atherosclerosis in Youth (PDAY)study. Atherosclerosis 160:441-448

23. Tsuruda T, Kato J, Hatakeyama K, Kojima K, Yano M, Yano Y, Nakamura K, Nakamura-Uchiyama F, Matsushima Y, Imamura T, Onitsuka T, Asada Y, Nawa Y, Eto T, Kitamura K (2008) Adventitial mast cells contribute to pathogenesis in the progression of abdominal aortic aneurysm. Circ Res 102:1368-1377

24. Theoharides TC, Alysandratos KD, Angelidou A, Delivanis DA, Sismanopoulos N, Zhang B, Asadi S, Vasiadi M, Weng Z, Miniati A, Kalogeromitros D (2012) Mast cells and inflammation. Biochim Biophys Acta 1822:21-33

25. Claesson-Welsh L (2015) Vascular permeability-the essentials. Ups J Med Sci 120:135-143

26. Alysandratos KD, Asadi S, Angelidou A, Zhang B, Sismanopoulos N, Yang H, Critchfield A, Theoharides TC (2012) Neurotensin and $\mathrm{CRH}$ interactions augment human mast cell activation. PLoS One 7:e48934

27. Tsuboi I, Harada T, Hirabayashi $Y$, Kanno J, Inoue T, Aizawa $S$ (2012) Age-related decline of mast cell regeneration in senescence-accelerated mice (SAMP1) after chemical myeloablation due to senescent stromal cell impairment. Exp Biol Med (Maywood) 237:1289-1297

28. Brownstein AJ, Ziganshin BA, Kuivaniemi H, Body SC, Bale AE, Elefteriades JA (2017) Genes associated with thoracic aortic aneurysm and dissection: an update and clinical implications. Aorta (Stamford) 5:11-20
29. Loeys BL, Dietz HC, Braverman AC, Callewaert BL, De Backer J, Devereux RB, Hilhorst-Hofstee Y, Jondeau G, Faivre L, Milewicz DM, Pyeritz RE, Sponseller PD, Wordsworth P, De Paepe AM (2010) The revised Ghent nosology for the Marfan syndrome. J Med Genet 47:476-485

30. Dyhdalo K, Farver C (2011) Pulmonary histologic changes in Marfan syndrome: a case series and literature review. Am J Clin Pathol 136:857-863

31. Sharma BK, Talukdar B, Kapoor R (1989) Cystic lung in Marfan's syndrome. Thorax 44:978-979

32. Hall JR, Pyeritz RE, Dudgeon DL, Haller JA Jr (1984) Pneumothorax in the Marfan syndrome: prevalence and therapy. Ann Thorac Surg 37:500-504

33. Turner JA, Stanley NN (1976) Fragile lung in the Marfan syndrome. Thorax 31:771-775

34. Enomoto N, Suda T, Kono M, Kaida Y, Hashimoto D, Fujisawa T, Inui N, Nakamura Y, Imokawa S, Funai K, Chida K (2013) Amount of elastic fibers predicts prognosis of idiopathic pulmonary fibrosis. Respir Med 107:1608-1616

35. Whimster WF (1970) The microanatomy of the alveolar duct system. Thorax 25:141-149

36. Bolande RP, Tucker AS (1964) Pulmonary emphysema and other cardiorespiratory lesions as part of the Marfan abiotrophy. Pediatrics 33:356-366

37. Nakashima Y (2010) Pathogenesis of aortic dissection: elastic fiber abnormalities and aortic medial weakness. Ann Vasc Dis 3:28-36

38. Gee MH, Gottlieb JE, Albertine KH, Kubis JM, Peters SP, Fish JE (1990) Physiology of aging related to outcome in the adult respiratory distress syndrome. J Appl Physiol 69:822-829

39. Seethala RR, Hou PC, Aisiku IP, Frendl G, Park PK, Mikkelsen ME, Chang SY, Gajic O, Sevransky J (2017) Early risk factors and the role of fluid administration in developing acute respiratory distress syndrome in septic patients. Ann Intensive Care 7:11

40. Danner RL, Elin RJ, Hosseini JM, Wesley RA, Reilly JM, Parillo JE (1991) Endotoxemia in human septic shock. Chest 99:169-175

41. Watkins TR, Nathens AB, Cooke CR, Psaty BM, Maier RV, Cuschieri J, Rubenfeld GD (2012) Acute respiratory distress syndrome after trauma: development and validation of a predictive model. Crit Care Med 40:2295-2303

42. Johnston CJ, Rubenfeld GD, Hudson LD (2003) Effect of age on the development of ARDS in trauma patients. Chest 124:653-659 